\title{
TRABALHO COMO PRINCÍPIO EDUCATIVO: REPRESENTAÇÕES SOCIAIS DE TRABALHO DE ALUNOS DO IFRO
}

\author{
WORK AS A EDUCATIONAL PRINCIPLE: SOCIAL REPRESENTATIONS OF IFRO \\ STUDENTS ABOUT WORK
}

\author{
J. A. P. de ANDRADE ${ }^{1, *}$, T. A. P. GONÇALVES ${ }^{2}$, R. O. M. AZEVEDO ${ }^{3}$
}

${ }^{1}$ Instituto Federal de Educação, Ciência e Tecnologia do Amazonas, Manaus, mestranda do Programa de Pós-graduação ProfEPT-Mestrado Profissional em Educação Profissional e Tecnológica, Brasil.

2 Instituto Federal de Educação, Ciência e Tecnologia do Amazonas, Manaus, mestranda do Programa de Pós-graduação ProfEPT-Mestrado Profissional em Educação Profissional e Tecnológica, Brasil.

${ }^{3}$ Instituto Federal de Educação, Ciência e Tecnologia do Amazonas, Manaus, docente e orientadora do Programa de Pós-graduação ProfEPT-Mestrado Profissional em Educação Profissional e Tecnológica, Brasil.

ARTICLEINFO

Article history:

Received 2018-07-02

Accepted 2018-08-17

Available online 2018-08-31
Palavras-chave: Trabalho e Educação. Representações Sociais. Formação Integral. Politecnia.

Keywords: Work and Education. Social Representations. Integral development. Polytechnic.

\section{*Autor correspondente: \\ E-mail:josefa.andrade@ifro.edu.br}

RESUMO. Este estudo objetivou conhecer as representações sociais sobre trabalho de alunos de dois campi do Instituto Federal de Educação de Rondônia - IFRO: Ji-Paraná (curso de Licenciatura em Química) e Colorado Oeste (curso de Licenciatura em Ciências Biológicas). Configura-se como descritivo e está embasado teoricamente pelas representações sociais. Os dados foram coletados a partir da aplicação de questionário e os resultados e informações foram apresentadas no texto com a seguinte organização: duas sessões, na primeira foi feita uma sucinta abordagem do trabalho e sua relação com a Educação Profissional e Tecnológica, tendo como base a concepção do Trabalho como princípio Educativo e uma breve discussão sobre formação para mercado de trabalho $X$ mundo do trabalho; na segunda são apresentadas as representações sociais dos alunos participantes da pesquisa. Os resultados mostraram que, para a maioria dos alunos, a função principal do trabalho é garantir a subsistência, considerando-o como um meio de se obter retorno financeiro e relacionando-o à aquisição de bens materiais. Destacou-se, embora de maneira menos expressiva a função que dois alunos deram para o trabalho: promover inclusão social. Pudemos conhecer as representações sociais de trabalho de alunos do IFRO, compreendendo que estas, são construídas de acordo com as experiências, interações e vivências que cada um tem ao longo da vida.

ABSTRACT. This study aimed to know the social representations of students from two campus of the Federal Institute of Education from Rondônia - IFRO about work: Ji-Paraná (Licentiate Degree in Chemistry) and Colorado do Oeste (Licentiate Degree in Biological Sciences). It's a descriptive research based on the theory of social representations. The data were collected from the questionnaire applica- 
tion and the results and information were presented in the text with the following organization: two sessions, the first was a brief approach to work and its relationship with Professional and Technological Education, based on the conception of Work as an educational principle and a brief discussion on preparation for the job market $X$ world of work; in the second, the IFRO is contextualized and the social representations of the students participating in the research are presented. The results showed that, for most students, the main function of the work is to guarantee subsistence, considering it as a means of obtaining a financial return and relating it to the acquisition of material goods. The role that two students gave to work was highlighted, although less expressively: to promote social inclusion. We were able to know the social representations of work of IFRO students, understanding that they are constructed according to the experiences, interactions and experiences that each one has throughout life.

\section{Introdução}

Para conhecer como se dão as diferentes concepções e significados do Trabalho na Educação Profissional e Tecnológica-EPT no contexto do Instituto Federal de Educação de Rondônia - IFRO, fez-se necessário conhecer quais as representações sociais de trabalho dos alunos envolvidos no processo.

As representações sociais foram utilizadas como metodologia porque "[...] traduzem a maneira como o grupo se pensa nas suas relações com os objetos que o afetam" (DURKHEIM, 1978 apud SANTOS, 2005, p. 81-82). Para Moscovici (1981) as representações sociais são conceitos, explicações que surgem através das relações e da comunicação entre os indivíduos. No contexto atual, Moscovici (1981) diz que as Representações Sociais podem ser comparadas com a mitologia, as crenças das sociedades antigas ou tradicionais, pois não se trata apenas da simples opinião desprovida de sentido, mas investidas dos significados advindos da interação entre o indivíduo e o mundo externo.

Por serem alunos da Educação Profissional e Tecnológica e sendo o Trabalho uma das bases conceituais da EPT, buscamos conhecer quais significações ele tem assumido no contexto do IFRO, a partir das representações sociais de alunos dos semestres finais dos cursos de Licenciatura em Química - campus Ji-Paraná e de Licenciatura em Ciências Biológicas - campus de Colorado Oeste.

Assim sendo, para melhor caracterizar o fenômeno estudado, nos utilizamos da pesquisa descritiva e esta, de acordo com Gil (2002) contribui para caracterizar determinado fenômeno, estabelecendo as relações existentes entre variáveis presentes na pesquisa. Teoricamente, pautou-se no estudo das representações sociais, adotando como referência central Moscovici (1981) e Santos (2005). Como instrumento de coleta de dados utilizamos a aplicação de um questionário com questões semiestruturadas. 
Dito isto, estruturamos este estudo em duas sessões: na primeira, fizemos uma breve contextualização de Trabalho, abordando sua relação com a educação; na segunda, contextualizamos o IFRO, local da pesquisa e apresentamos as representações sociais de Trabalho dos alunos participantes da pesquisa.

\section{Trabalho e Educação}

De acordo com o Dicionário de Língua portuguesa o significado de Trabalho remete à ação, labutação, lida e se refere a uma ocupação manual ou intelectual (FERREIRA, 2001). Enquanto um dos princípios base da EPT-Educação Profissional e Tecnológica, o significado de Trabalho ultrapassa o sentido de produção material, posto que assume também outras dimensões, como as dimensões social, política, ética e cultural (ARRUDA, 2012).

Compreendido enquanto princípio educativo, o Trabalho está diretamente relacionado à educação, nesse sentido, para fortalecer essa relação se faz necessário "[...] superar a noção de que a educação tem um objeto em si mesma e, portanto, subordina o trabalho enquanto outro polo da relação" (ARRUDA, 2012, p. 96-97). Dito isso, entendemos que Trabalho e educação caminham juntos.

Já por Educação, de acordo com o Dicionário da Língua portuguesa, compreende-se como sendo o processo onde o homem tem as capacidades, física, intelectual e moral desenvolvidas (FERREIRA, 2001). Disso, entendemos que a Educação é um processo que afeta o ser humano em todas as dimensões, contrariando o senso comum, onde a ela são atribuídas apenas a função que implica em formação intelectual.

Dito isto, entendendo que Educação e Trabalho são processos complementares nhoque tange à formação humana, enquanto pelo trabalho o homem produz sua existência, é pela educação que ele se capacita para este existir e para o produzir-se (ARRUDA, 2012).

\subsection{Trabalho como princípio educativo}

A relação homem e trabalho acompanha os primórdios da história da humanidade, porém modificou-se drasticamente com o passar dos tempos, principalmente com o que denominamos de desenvolvimento da sociedade de consumo. A princípio, o trabalho garantia a subsistência, ou seja, o que era produzido garantia a sobrevivência da comunidade ou grupo, não havia lucro, não gerava exploração, era o que realmente devia ser, necessidade para a existência. Ou seja, "[...] o ato de agir sobre a natureza transformando-a em função das necessidades humanas é o que conhecemos com o nome de trabalho" (SAVIANI, 2007, p. 154). 
Neste sentido, o trabalho pode ser caracterizado como a própria essência humana (SAVIANI, 2007) e enquanto essência humana, somente pode ser realizado pelo homem, não sendo outro animal capaz de fazê-lo. (SAVIANI, 2007).

Nas sociedades primitivas, aquilo que hoje conhecemos como escolas, não existia, mas o ofício sim, então perguntamos: Como os homens se educavam? Pelo próprio trabalho. Os mais velhos ensinavam o que sabiam aos mais novos e assim o conhecimento dava-se na prática, pela ação, por isso Saviani (2007) diz que, desde os primórdios da história, o que diferencia o homem dos outros animais é a faculdade de, diante de uma necessidade, através do seu trabalho, modificar a natureza.

Por um longo tempo na história da humanidade essa lógica de educação através do trabalho perdurou-se, porém, com o advento da propriedade privada e a divisão da sociedade em classes, essa estrutura se desmancha e há uma ruptura entre trabalho e educação. É sob a influência dessa divisão de classes que surge a escola. Assim, ela não surge universal, como direito de todos, muito pelo contrário, ela surge para atender os filhos da classe proprietária, que dispõem de tempo para frequentá-la. Aos filhos dos não proprietários, cabe a educação adquirida no próprio processo do trabalho e apenas para o trabalho.

$\mathrm{Na}$ escola de hoje percebemos que, no Ensino Fundamental, segundo o que aponta Saviani (2007), o trabalho é tratado com princípio educativo, pois é inerente à escola elementar, a relação entre ele e a educação é implícita. Já no Ensino Médio, essa relação deve ser tratada de maneira explícita, ela deve ser a base para se organizar um currículo.

Como afirma Pacheco (2012, p. 67) "considerar o trabalho princípio educativo equivale a dizer que o ser humano é produtor de sua realidade e, por isso, apropria-se dela e pode transformá-la". Neste sentido, o trabalho como princípio educativo, implica compreender que o homem é o sujeito da sua própria realidade e que o trabalho é a ponte intermediaria entre o homem e a sua realidade. (PACHECO, 2012).

\subsection{Mercado de Trabalho X Mundo do Trabalho}

Hoje, a concepção que se tem de trabalho está diretamente relacionada as concepções históricas tanto de educação quanto de formação profissional. Essas concepções, muitas vezes, têm como foco a formação do indivíduo para atender as necessidades do mercado e este, por sua vez, muitas vezes opressor e desigual, contribui para que essas contrariedades, principalmente, quanto ao sentido do trabalho, sejam perpetuadas.

$\mathrm{Na}$ atualidade, utilizando-se das concepções de uma pedagogia centrada nas competências do indivíduo, ele é viso como único responsável por sua ascensão social e inserção 
no mercado trabalho, o foco é a empregabilidade. E quando não se consegue inserir no mercado de trabalho, a carga de responsabilidade recai sobre e a falta de preparo. Tal situação é utilizada para justificar as desigualdades sociais (FRIGOTTO, 2005). Nessa concepção, o trabalho é compreendido apenas como garantia de subsistência, como uma ação necessária para suprir a necessidade e garantir a sobrevivência e contribui com a ideia reducionista de que a formação profissional prepara para o mercado de trabalho e não para o mundo do trabalho.

A formação para o mundo do trabalho, consiste na formação do indivíduo a partir da concepção de trabalho na esfera da necessidade, mas também da liberdade (FRIGOTTO, 2005). O autor acrescenta que essa concepção de trabalho, o torna um dever, mas também um direito e que, através dele, acontece um processo formativo ou educativo. Essa formação para o mundo do trabalho tem como norteadora a concepção do sujeito completo, onde ao processo são agregados valores, cultura, ciência, tecnologia e a concepção do trabalho como emancipador, por meio do qual ele faz e se faz.

\section{A Representação Social de Trabalho de alunos do IFRO}

Tendo como base Wolfgang (1995) quando diz que o conceito de representação social é multifacetado, pois é processo social, mas também é constructo pessoal, buscamos conhecer a representação social do Trabalho no IFRO à luz das representações de vinte e quatro alunos dos cursos de Licenciatura em Ciências Biológicas, acadêmicos dos campi de Ji-Paraná e Colorado do Oeste, respectivamente.

Nos utilizamos da aplicação de um questionário, composto por quatro questões discursivas e por uma questão objetiva, tendo como objetivo conhecer quais as representações o aluno tem de Trabalho no contexto da EPT. O questionário foi aplicado durante o horário de aula nas duas turmas, no período noturno e teve duração média de trinta minutos. Aos alunos foi explicado o objetivo da pesquisa, bem como foi apresentado o Termo de Livre Consentimento e, em seguida, todos os presentes, vinte e quatro alunos, disponibilizaram-se a responder.

Tratamos neste item das respostas fornecidas à questão objetiva: "Sua formação acadêmica, possibilita uma formação para o mercado de trabalho ou para o mundo do trabalho? " e também apresentamos um quadro com as respostas concedidas pelos alunos quanto às perguntas discursivas: "Na sua visão, O que é trabalho? E qual sua função? ". 
Quadro 1 - Conceituação de trabalho a partir das representações sociais dos alunos entrevistados

\section{Respostas dadas à pergunta: Na sua visão, o que é trabalho? E qual a sua função?}

"trabalho é aquilo que as pessoas lutam com amor para adquirir bens"

"Trabalho é toda atividade realizada com algum objetivo. Minha função é contribuir para com a sociedade da forma que for mais conveniente."

"De uma maneira geral trabalho é uma atividade que a pessoa realiza. Existe várias funções, mais posso citar a inclusão da pessoa no meio social."

"O trabalho é algo a ser realizado, tendo como função inserir as pessoas em círculos de convivência, obtenção de renda para se manter."

"Trabalho é algo que fazemos para ter renda que nos possibilita adquirir bens; uns satisfação pessoal."

"Trabalho está relacionado a prestação de serviços."

"Toda e qualquer ação que o ser humano realiza, com a função de ajudar, melhorar o meio em que vivemos."

"Trabalho de certa forma é o que o ser humano faz para sobreviver. O trabalho insere o homem na sociedade também."

"Trabalho é a ação de exercer um cargo em determinada área de uma empresa. Tem por função gerar um retorno econômico, pois seria uma prestação de serviços."

"Trabalho é qualquer atividade em que se "gasta" tempo e requer esforço afim de uma remuneração após essa atividade."

"E qualquer ato exercido em troca de outra coisa, seja dinheiro, alimento, laser. Tem a função de fazer que o "mundo" de finanças gire."

"Trabalho são as ações realizadas para mover a economia do planeta, seja ele formal ou informal. Mera subordinada de um governo capitalista, que faz dos trabalhadores marionetes nas bases das hierarquias, com mão de obra barata."

"É uma forma de exercício legal exercida pelos cidadãos. Talvez sua principal função seja propiciar subsídios para as pessoas que o realiza."

" "trabalho" eu compreendo como algo que dá sentido ou o que eu faço é um "trabalho", coisa que não gosta de fazer. A função do trabalho, tem a necessidade para a sobrevivência e não gosta, diferente pois tem pessoas que trabalham e gostam do que faz e não considera um trabalho, uma coisa maçante."

"Trabalho é a meta de se construir algo seja material, intelectual ou espiritual desde que traga um retorno para o trabalhador sendo-a dinheiro ou apenas o prazer de fazer, construir, conquistar. Atualmente sou vistoriador de veículos nos Detran."

"Trabalho: forma de garantir a subsistência de um indivíduo."

"Conjunto de atividades realizadas, com o objetivo de atender uma meta (atingir)."

"Trabalho é a atividade que desenvolvemos e para a qual nos qualificamos, como forma de sobrevivência. Pode ser designado também como qualquer atividade desenvolvida regularmente, remunerada ou não."

"É todo exercício legal remunerado. Propiciar uma hierarquia social, para que o sistema funcione."

"Trabalho é você exercer uma função na sociedade baseado em sua formação ou habilidade, com o intuito de nos ajudar financeiramente."

"É do trabalho que o ser humano tira seu sustento. Ele é muito importante, pois ocorre também uma interação com o meio, aprendemos a construir relações novas."

"Trabalho é desenvolver algum papel em prol de algo."

"Tudo aquilo que eu faço no dia-a-dia. A função nos proporcionar melhor qualidade de vida e sobrevivência."

"O trabalho dignifica o homem como a própria sociologia nos ensina. Sua função é constante e permanente em nossas vidas onde exercitamos a arte de conviver em sociedade."

Fonte: questionário da pesquisa, 2017. 
Ao analisar os questionários respondidos pelos alunos participantes da pesquisa, percebemos que um número considerável de respostas demonstra que os entrevistados relacionam como principal função do trabalho a subsistência, sendo ele considerado apenas um meio para se obter retorno financeiro e/ou proporcionar aquisição de bens materiais o que, também remete a subsistência ou suprimento das necessidades. Do analisado, apenas dois entrevistados relacionam o trabalho à satisfação pessoal e bem-estar. Outros dois chamam a atenção para o fato de o trabalho ser visto um meio para se promover a inclusão social.

Destacaram-se as respostas de dois entrevistados que relacionaram o trabalho à hierarquização da sociedade, ou seja, o trabalho é compreendido como um meio pelo qual as relações de desigualdades sociais se matem. Nos chama a atenção a concepção apresentada por um dos participantes, este menciona o fato de o trabalho ser algo que a pessoa faz simplesmente para garantir a sobrevivência e que é uma atividade de que não gosta. Tal representação nos remete ao conceito de tripalium, discutido por Nosella (2012), em que o trabalho humano é concebido como um castigo, algo que causa dor e sofrimento e que, portanto, não é visto como atividade educativa tão pouco prazerosa.

Quando foram levantadas as respostas dadas à questão objetiva "Sua formação acadêmica, possibilita uma formação para o mercado de trabalho ou para o mundo do trabalho?" Pudemos compreender as representações de Trabalho apresentadas pelos participantes. A seguir, apresentamos um quadro com os dados referentes as repostas dos participantes.

Quadro 2 - Formação para o Mercado de Trabalho ou para o Mundo do Trabalho

\begin{tabular}{|l|c|c|c|}
\hline $\begin{array}{l}\text { Número de } \\
\text { alunos } \\
\text { Participantes }\end{array}$ & $\begin{array}{l}\% \text { de alunos que } \\
\text { afirmaram estarem se } \\
\text { formando para o } \\
\text { Mercado de Trabalho }\end{array}$ & $\begin{array}{l}\% \text { de alunos que } \\
\text { afirmaram estarem se } \\
\text { formando para o o de alunos que afirmaram } \\
\text { Mundo do Trabalho }\end{array}$ & $\begin{array}{l}\% \text { estarem se formando para o } \\
\text { Mercado de Trabalho e para o } \\
\text { Mundo do Trabalho }\end{array}$ \\
\hline $\begin{array}{c}22 \\
\text { acadêmicos }\end{array}$ & $71 \%$ & $21 \%$ & $8 \%$ \\
\hline
\end{tabular}

Fonte: questionário da pesquisa, 2017.

A partir do quadro, percebemos que para aproximadamente $71 \%$ dos acadêmicos participantes da pesquisa sua formação está voltada para atender ao mercado de trabalho. Enquanto que para cerca de $21 \%$ deles, a formação acadêmica que recebem está voltada para o mundo do trabalho. Aproximadamente $8 \%$ dos participantes afirmaram estarem sendo formados para o mercado de trabalho e também para o mundo do trabalho. Embora, ainda de forma preliminar, podemos afirmar que existe uma relação entre as representações sociais de Trabalho apresentada pelos participantes, e a compreensão que eles têm da sua de formação enquanto alunos da ETP no IFRO. 


\section{Considerações finais}

Ao discutirmos a Educação Profissional e Tecnológica e ao conhecermos suas bases, abrangência e atuação no processo de formação profissional dos alunos das instituições federais de ensino, surgiu a necessidade de conhecer qual o olhar do aluno para a EPT. Essas inquietações, nos fizeram questionar vários aspectos da atuação do IFRO, emergindo a ideia de conheceras representações sociais de alunos sobre alguns aspectos da sua formação, neste caso, conhecemos as representações sociais sobre trabalho.

Através da breve discussão apresentada, conhecemos as representações sociais de alunos finalistas de dois campuses do Instituto Federal de Educação de Rondônia - IFRO sobre Trabalho, especificamente, sobre sua função: Ji-Paraná (curso de Licenciatura em Química) e Colorado Oeste (curso de Licenciatura em Ciências Biológicas). As representações sociais dos alunos sobre trabalho e sua função, mostraram que, para a maioria dos alunos, a função principal do trabalho é garantir a subsistência. Para esses alunos, o valor do trabalho foi associado a obtenção de retorno financeiro e a aquisição de bens materiais.

Ao relacionarmos essas informações com as respostas que buscaram conhecer, na opinião dos participantes, qual o objetivo de sua formação, se era uma formação para o mercado de trabalho ou para o mundo do trabalho, identificamos que há uma relação muito forte entre as representações sociais de trabalho que têm os alunos e o tipo de formação a eles oferecida: uma formação para atender as necessidades do mercado de trabalho.

Diante desse estudo inicial, que teve como objetivo principal conhecer as representações sociais de trabalho de alunos do IFRO, consideramos que tais informações devem servir de orientação para questionamentos maiores, devendo servir como um norte para discussões de cunho institucional onde se possa abrir para discussão qual o tipo de educação profissional e tecnológica estamos ofertando e, principalmente, que tipo de profissionais estamos formando.

\section{Agradecimentos}

Agradecemos ao IFRO - Instituto Federal de Rondônia pelo auxílio ofertado através do PIQ - Plano de Auxílio à Qualificação e aos participantes da pesquisa, acadêmicos dos 
cursos de Licenciatura em Química do campus de Ji-Paraná e acadêmicos do curso de Ciências Biológicas do campus de Colorado do Oeste, ambos em Rondônia

\section{Referências}

ARRUDA, Marcos. A articulação trabalho-educação visando uma democracia integral. In: GOMEZ, Carlos Minayo et al. Trabalho e conhecimento: dilemas na educação do trabalhador. 6. ed. São Paulo: Cortez, 2012.

FERREIRA, Aurélio Buarque de Holanda. Miniaurélio século XXI escolar: o minidicionário da língua portuguesa. rev. e ampl. Rio de Janeiro: Nova Fronteira, v. 2, 2001.

FRIGOTTO, Gaudêncio; CIAVATTA, Maria; RAMOS, Marise (Org.). Ensino médio integrado: concepção e contradições. Cortez Editora, 2005.

FRIGOTTO, Gaudêncio. Trabalho, conhecimento, consciência e a educação do trabalhador: impasses teóricos e práticos. In: GOMEZ, Carlos Minayo et al. Trabalho e conhecimento: dilemas na educação do trabalhador. 6. ed. São Paulo: Cortez, 2012.

MINAYO, Maria Cecília de Souza. O conceito de representações sociais dentro da sociologia clássica. In: GUARESCHI, Pedrinho; JOVCHELOVITCH, Sandra (Org.). Textos em representações sociais, v. 7, p. 89-111, 1995.

MOSCOVICI, Serge. On Social Representatios. In: FORDAS, J.P. (eds.) Social cognition: perspectives on everyday unbdestanding. London; Academic Press, 1981, p.181-209.

NOSELLA, Paolo. Trabalho e Educação. In: GOMEZ, Carlos Minayo et al. Trabalho e conhecimento: dilemas na educação do trabalhador. 6. ed. São Paulo: Cortez, 2012.

NUNES DURÃES, Marina. Educação técnica e educação tecnológica múltiplos significados no contexto da educação profissional. Educação \& Realidade, v. 34, n. 3, 2009.

SAVIANI, Dermeval. Trabalho e educação: fundamentos ontológicos e históricos. Revista Brasileira de Educação, v. 12, n. 34, p. 152-165, 2007.

WAGNER, Wolfgang. Descrição, explicação e método na pesquisa das representações sociais. Textos em representações sociais, v. 7, p. 149-186, 1995. 